\title{
Undergraduate allergy teaching in a UK medical school: Comparison of the described and delivered curriculum
}

\author{
Yasser Shehata, Michael Ross, Aziz Sheikh*
}

\author{
Division of Community Health Sciences: GP Section, University of Edinburgh, 20 West Richmond St, \\ Edinburgh EH8 9DX, UK
}

Received 28 September 2006; accepted 14 November 2006

\begin{abstract}
KEYWORDS
Allergy;

Medical education;

Curriculum mapping;

Described/delivered

curricula

Abstract:

Background: Concerns have been raised about the adequacy of allergy teaching in UK undergraduate medical curricula. Our previous work, which involved undertaking a systematic analysis of the documented curricular learning objectives relating to allergy teaching in a UK medical school, found references to allergy teaching in each of the five years of study but also identified some apparent omissions in allergy teaching. These may represent actual gaps in relation to allergy training, or alternatively may reflect dissonance between the described and delivered curricula. Objective: To compare the described and delivered undergraduate curricula on allergy and allergy-related topics in a UK medical school.

Methods: We identified and e-mailed the individuals responsible for each of the 43 modules in the five-year undergraduate medical programme at the University of Edinburgh, enquiring about the delivery of allergy-related teaching within their modules. We then compared these responses with the results of the previous study mapping allergy-related teaching across the undergraduate curriculum.

Results: Fifty-one individuals were identified as being responsible for leading the 43 modules in the curriculum. Forty-nine $(96 \%)$ of these module organisers responded to our enquiry; these individuals represented 41 of the 43 modules (95\%). Module organisers reported that allergy-related teaching and learning was delivered in 14 modules (33\%), was absent in $13(30 \%)$ modules, and may occur to varying degrees within a further $10(23 \%)$ modules. Module organisers' responses about the delivered curriculum on allergy were consistent with the findings from documented learning objectives in $21(49 \%)$ modules. They also reported allergy teaching and learning in modules which had not been identified by examination of the learning objectives; however, there were still important gaps in the allergy-related curriculum.
\end{abstract}

\footnotetext{
* Corresponding author: Tel: +44 (0)131 651 4151; fax: +44 (0)131 6509119

E-mail address: aziz.sheikh@ed.ac.uk
} 
Conclusions: Information gathered from teaching staff confirms that specific teaching and learning on allergic disorders is currently being delivered in all five years of the undergraduate curriculum. However, comparison between the described and delivered curricula on allergy revealed discrepancies highlighting the complex nature of the undergraduate curriculum and the difficulties involved in mapping specific teaching themes within them. This assessment has revealed gaps in allergy training which need to be addressed.

(c) 2006 General Practice Airways Group. All rights reserved.

\section{Introduction}

Despite the high prevalence of allergic disorders in the UK, and poor access to consultant allergists to whom general practitioners (GPs) and others can refer, there has been little empirical work on the nature and extent of allergy teaching in the undergraduate medical curriculum. ${ }^{1,2}$ In a previous analysis of the described medical curriculum, we found that allergic disorders featured in each of the five years of the University of Edinburgh's medical curriculum, but there were some aspects of allergy teaching which were not represented in the documented learning outcomes. ${ }^{3}$ Many authors have highlighted the potential for discrepancy between the 'described' or 'intended' curriculum, the 'delivered' or 'taught' curriculum and the 'experienced' or 'received' curriculum, ${ }^{4,5}$ and although this can be minimised through constructive alignment, some degree of discrepancy is probably inevitable.

As with most medical schools in the UK, Edinburgh moved towards an integrated outcomes-based curriculum in response to the General Medical Council's document Tomorrow's doctors. ${ }^{6,7}$ This has led to curriculum planners deciding the learning outcomes that students should achieve by graduation, then using these to define the content, teaching and learning, assessment and evaluation of the course. . $^{4,8}$ Topics are integrated to varying degrees, but there is a move towards teaching and learning experiences in which traditionally separate disciplines are taught together along with some of the newer themes such as communication skills in modules or systems. An example of this is the grouped teaching of the anatomy, physiology, biochemistry, pathology, microbiology, social and clinical sciences relating to each of the body systems in the first two years in Edinburgh. Themes and body systems are revisited in later years, building on students' existing knowledge and understanding in a constructivist manner. ${ }^{9-12}$ Although outcomesbased integrated education has been shown to enhance students' learning experience, there is the potential for the individual perspective of traditional disciplines such as immunology to be lost by teaching components of it separately. ${ }^{13,14}$ Edinburgh has also adopted the recommended 'core curriculum with options' model, in which up to one-third of the curriculum is 'student selected' - allowing students to become more self-directed and to develop their own interests and research skills. ${ }^{7,15}$ This approach can also enhance student learning experience and engagement, but does mean that each student will gain a slightly different overall experience during their course. Only a few are likely to focus primarily on allergic disorders during some of these studentselected components. By grouping and integrating teaching and learning into certain themes, there will inevitably be other topics which will span several themes and risk becoming disintegrated. Various tools and approaches have been employed to identify and develop the content of topics that span curricular themes. Those reported in the literature include modified Delphi studies, questionnaires, curriculum mapping, concept mapping and also a specific tool which was developed to evaluate curricula for education on palliative care. ${ }^{16-19}$

In the present study, we sought to compare the described curriculum (documented by the learning objectives) with the delivered curriculum (the teaching and learning reported by those responsible for each of the modules) relating to allergic disorders at the University of Edinburgh Medical School.

\section{Methods}

We identified the individuals responsible for the 43 horizontal modules and vertical themes which constitute the five-year undergraduate medical programme described in the previous study. ${ }^{3}$ Each of these individuals was e-mailed up to a maximum of three times between February and May 2006, and 
they were asked whether or not there was any allergy or allergy-related teaching and learning in their respective modules. Non-responders were sent a reminder e-mail two weeks later. Responses from multiple organisers of the same module were combined. All responses were scrutinised for duplication, as might easily occur when obtaining responses from integrated horizontal modules and vertical themes, and when any such duplication occurred the opportunities were considered to be only in the horizontal module. Because some of the responses from module organisers and course leaders suggested a lack of consensus on what constituted an allergic disorder, we sent a third and final e-mail to the entire sample clearly specifying the disease processes/conditions of interest (Table 1), asking for any amended or additional information.

Responses were analysed independently by two medically qualified physicians and grouped into one of the following four categories:

a) Yes (there is some well-defined allergy teaching and learning within the module).

b) No (there is no formal allergy teaching and learning within the module).

c) Possible (they are not aware of any formal allergy-related teaching and learning in the module for all students, but some learning opportunities may arise).

d) No additional information (either referral to course documentation or no response).

Disagreements between the two independent assessors were resolved through discussion, with arbitration conducted by a third assessor if agreement could not be reached.

Table 1 Areas of allergy teaching enquired about

\begin{tabular}{ll}
\hline Allergens & Hayfever \\
Allergic conjunctivitis & $\begin{array}{l}\text { Hypersensitivity } \\
\text { Occupational } \\
\text { Allergies }\end{array}$ \\
& $\begin{array}{l}\text { allergy/asthma } \\
\text { Allergy diagnosis }\end{array}$ \\
Anaphylaxis & Perennial rhinitis \\
Angioedema & Seasonal rhinitis \\
Asthma & Skin-prick testing \\
Atopy & Urticaria \\
Desensitisation & \\
Eczema & Any other aspect of \\
& allergy \\
\hline
\end{tabular}

Responses from module organisers about the delivered curriculum were cross-tabulated with the analysis of the documented learning objectives in our previous study, ${ }^{3}$ and then the two were combined. If there were discrepancies when combining data, the module organiser's responses were afforded more weight than the documented learning objectives. Where no additional information was provided by the module organiser, the findings from the learning objectives were used.

\section{Results}

Fifty-one module organisers/theme leaders were identified as representing the 43 taught modules of the University of Edinburgh $\mathrm{MBChB}$ course. These 51 individuals actually had 56 'roles', as 47 were responsible or partly responsible for a single module, three were responsible for two modules, and one was responsible for three modules. Thirty-eight of the modules had a single organiser, four had two organisers, and one had eight organisers. This latter module, 'Clinical Skills Personal Professional Development' (CSPPD), is a collection of eight overlapping sub-themes which are led by different individuals.

We obtained responses from 49 (96\%) of the module organisers and course leaders, thus representing 41 of the 43 (95\%) courses and modules. Six of those who had previously responded sent another response following our third e-mail clarifying what we would consider to be allergy-related topics. Of these, three responses remained 'possible', two remained 'yes' and one changed from 'possible' to 'yes'.

Teaching and learning of allergy topics was reported as being delivered in 14 modules (33\%), possibly delivered in 10 modules $(23 \%)$ and absent from 13 modules (30\%). No additional information beyond that contained in the learning objectives was supplied for 6 modules (14\%).

Comparison of the described curriculum ${ }^{3}$ with the module organiser responses regarding the delivered curriculum revealed significant discrepancies (see Table 2). Of the 11 modules (26\%) found to have learning objectives relating to allergy, module organisers confirmed that allergy teaching and learning was being delivered in eight (19\%), possibly delivered in one $(2 \%)$, and added no new information about two modules (5\%). Of the 32 modules (74\%) which did not have learning outcomes relating to allergy, module organisers reported that allergy teaching and learning was being delivered in six (14\%), possibly delivered in nine $(21 \%)$, not being delivered in $13(30 \%)$, and 
Table 2 Organiser's responses relating to allergy teaching within course modules

\begin{tabular}{|c|c|c|c|c|}
\hline & Module/Theme & $\begin{array}{l}\text { Allergy objectives } \\
\text { in described curriculum }\end{array}$ & $\begin{array}{l}\text { Organiser's } \\
\text { response }\end{array}$ & $\begin{array}{l}\text { Combined } \\
\text { response }\end{array}$ \\
\hline Years 1 & Introduction to life & Yes & Yes & Yes \\
\hline \multirow[t]{12}{*}{ and 2} & Cardiovascular Health & No & No additional info & No \\
\hline & Respiration & Yes & Yes & Yes \\
\hline & Bones \& Joints & No & No & No \\
\hline & Neuroscience & No & No & No \\
\hline & Nutrition & No & Possible & Possible \\
\hline & Clinical Genetics & No & No & No \\
\hline & Renal & No & Possible & Possible \\
\hline & Endocrinology & No & No additional info & No \\
\hline & The Virtual Clinic & No & No additional info & No \\
\hline & Introduction to Clinical Practice & Yes & Yes & Yes \\
\hline & Health \& Society & No & Possible & Possible \\
\hline & Problem Based Learning & Yes & Yes & Yes \\
\hline \multirow[t]{5}{*}{ Year 3} & Locomotor System & No & No & No \\
\hline & Gastroenterology & No & Possible & Possible \\
\hline & Respiratory System & Yes & Yes & Yes \\
\hline & Cardiovascular System & No & Possible & Possible \\
\hline & Psychiatry & No & No & No \\
\hline \multirow[t]{13}{*}{ Year 4} & Oncology \& Palliative Care & No & No & No \\
\hline & Psychiatry & No & No & No \\
\hline & Neurology & No & No & No \\
\hline & General Practice & No & Possible & Possible \\
\hline & Obstetrics \& Gynaecology & No & Possible & Possible \\
\hline & Renal Medicine & No & Possible & Possible \\
\hline & Urology & No & No & No \\
\hline & Haematology & No & No & No \\
\hline & Breast & No & No & No \\
\hline & Otolaryngology & Yes & Yes & Yes \\
\hline & Dermatology & Yes & Yes & Yes \\
\hline & Ophthalmology & No & Yes & Yes \\
\hline & Genitourinary Medicine & No & Yes & Yes \\
\hline \multirow[t]{7}{*}{ Year 5} & Child Life \& Health & No & Yes & Yes \\
\hline & Geriatric Medicine & No & No additional info & No \\
\hline & General Practice & Yes & Possible & Possible \\
\hline & Acute \& General Medicine & Yes & No additional info & Yes \\
\hline & General Surgery & Yes & No additional info & Yes \\
\hline & Anaesthetics, Critical care, A\&E & No & Yes & Yes \\
\hline & Preparing for Practice & No & Yes & Yes \\
\hline Vertical & Pharmacology and Therapeutics & Yes & Yes & Yes \\
\hline \multirow[t]{5}{*}{ Themes } & Social Sciences and Public Health & No & No & No \\
\hline & Psychological Aspects of Medicine & No & No & No \\
\hline & Student Selected Components & No & No & No \\
\hline & Clinical Skills, Personal & No & Possible & Possible \\
\hline & Professional Development & No & Yes & Yes \\
\hline
\end{tabular}


added no new information about four modules (9\%). For 21 modules (49\%), therefore, the declared learning objectives matched the module organiser responses about the delivered curriculum.

Combining data from the previous study on learning objectives with the module organiser responses revealed that there were learning opportunities on allergy topics in 16 modules (37\%), possibly learning opportunities in 10 modules (23\%), and apparently no learning opportunities for allergy topics in 17 modules (40\%) of the five-year $\mathrm{MBChB}$ course.

Detailed analysis of the learning objectives and module organiser responses indicates that some areas of allergy teaching are currently being covered in the curriculum. The patho-physiology of allergy with coverage of normal and abnormal immune responses, allergies to drugs, adhesive dressings, topical anti-septic solutions and latex allergy in male catheterisation were, for example, all identified. Asthma, extrinsic allergic alveolitis and other immune-mediated hypersensitivity reactions in the lung, hayfever and allergic rhinitis, atopic and contact dermatitis, urticaria, allergic conjunctivitis and anaphylaxis were also clearly identified.

We did not, however, identify any formal teaching or learning opportunities relating to: angioedema; insect allergies; food allergies; the interpretation of main diagnostic allergy tests such as skin prick tests and serum specific IgE; certain therapeutic approaches such as immunotherapy; teaching on how to manage co-morbidity; or when to refer to a specialist allergist.

\section{Discussion}

This survey of module organisers has confirmed that allergy and allergy-related disorders do feature throughout the five years of the undergraduate medical course at the University of Edinburgh, and that each student is receiving at least some allergy-related teaching and opportunities in $37-60 \%$ of modules within the course. There is also evidence that some aspects of allergy teaching are being comprehensively delivered in the University of Edinburgh medical programme, although others are not. There is currently no consensus on a best practice curriculum for undergraduate allergy teaching. We feel that 'first level' competencies of the recent provisional statement by the World Allergy Organisation could be a useful resource for curriculum planning in this area. ${ }^{14,20}$ This mapping exercise has highlighted some first-level com- petencies which are not currently taught in the Edinburgh medical curriculum, and will provide a springboard for debate about an appropriate undergraduate allergy curriculum.

We have also highlighted significant discrepancies between described and delivered curricula, consistent with a previous study mapping cultural competency from multiple perspectives in an undergraduate curriculum. ${ }^{5}$ This again highlights the fact that curriculum mapping and evaluation from a single perspective can be misleading.

\section{Main strengths and limitations of this work}

The principal strengths of this work are the comprehensive survey of all course leaders and module organisers who are directly involved in the planning, teaching and evaluation of their modules, and the very high response rate. Building on our previous work, ${ }^{3}$ this assessment probably represents the most comprehensive assessment of undergraduate training in allergy undertaken to date.

The main limitation of this work is that it was confined to one medical school. The gaps in training uncovered, however, map almost completely onto areas of care provision in which UK GPs have expressed concerns about their own confidence and competencies, ${ }^{2}$ thus suggesting that our findings from this study are unlikely to be specific to Edinburgh. Other limitations are that we focused on stated formal allergy teaching and did not assess the quality or fine detail of the training, or students' actual knowledge, attitudes or skills in allergy (the 'experienced' or 'learned' curriculum). In-depth interviews with module organisers rather than a survey could also have enhanced the study, and some assessment of students' understanding about allergy would also have added information about the 'experienced' curriculum.

\section{Conclusions: Implications for curriculum development and research}

Given the frequency of allergy, its typical multiorgan manifestations, and the lack of informal and specialist clinical training opportunities available, it is important that a coherent approach to training in allergy is developed across undergraduate and postgraduate medical curricula. It is important to identify what areas and levels of competence are needed by graduates, so that these can be highlighted and developed in the undergraduate curriculum. Postgraduate training would then ensure that their knowledge and skills are developed to the standards required of GPs and 
consultants in different specialities. Identifying and developing allergy as a vertical curriculum element should be relatively straightforward in the Edinburgh programme. This would involve appointing an advocate, negotiating learning objectives, and developing the 'curriculum map' we have created on the managed learning environment to emphasise to students and staff how and where allergic disorders are taught. Such a map highlights any omissions or weaknesses in the curriculum, which can then be considered and addressed.

We now plan to develop the teaching of allergy at the University of Edinburgh Medical School in consultation with our junior doctors, clinical teachers, medical students from different years, and, importantly, patients who have the misfortune of living with allergic problems.

\section{Funding}

None

\section{Contributorship}

AS conceived the idea for this study and together with MR devised the methodology. YS and MR undertook data analysis. All three authors were involved in writing the paper.

\section{Potential conflict of interests}

AS gave evidence to the Health of Commons Health Committee review on The provision of allergy services, was part of the Department of Health Allergy Review Stakeholder Group and serves on the Scottish Executive's Review of Allergy Services in Scotland Working Group. MR is a member of the University of Edinburgh's Medical Teaching Organisation. YS has no conflicts of interest.

\section{Acknowledgments}

Our thanks to all module organisers and course leaders who provided us with relevant information about their courses. Without their cooperation, this work couldn't be done. Also thanks to $\mathrm{Dr}$ Helen Cameron (director of the Medical Teaching Organisation) for her helpful comments on an earlier draft of this paper.

\section{References}

1. Gupta R, Sheikh A, Strachan DP, Anderson HR. Burden of allergic disease in the UK: secondary analyses of national databases. Clin Exp Allergy 2004;34:520-6.

2. Levy ML, Price D, Zheng X, Simpson C, Hannaford P, Sheikh A. Inadequacies in UK primary care allergy services: National survey of current provisions and perceptions of need. Clin Exp Allergy 2004;34:518-19.

3. Shehata $Y$, Ross $M$, Sheikh A. Undergraduate allergy teaching in a UK medical school: mapping and assessment of an undergraduate curriculum. Prim Care Resp J 2006;15:173-8.

4. Prideaux $D . A B C$ of learning and teaching in medicine: curriculum design. BMJ 2003;326:268-70.

5. Wachtler C, Troein M. A hidden curriculum: mapping cultural competency in a medical programme. Medical Education 2003;37:861-8.

6. General Medical Council. Tomorrow's doctors. London: GMC, 1993.

7. General Medical Council. Tomorrow's doctors. London: GMC, 2002. Available from: http://www.gmc-uk.org/ education/undergraduate/tomorrows_doctors.asp

8. Smith SR, Dollase R. Planning, implementing and evaluating a competency-based curriculum. Medical Teacher 1999;21:12-22.

9. Bligh J. Identifying the 'core' curriculum: the Liverpool approach. Med Teach 1995;17:383-90.

10. Bligh J. Curriculum design revisited. Medical Education 1999;22:82-5.

11. Harden RM, Stamper N. What is a spiral curriculum? Med Teach 1999;21:141-3.

12. Harden RM. Curriculum Mapping: a tool for transparent and authentic teaching and learning. AMEE Education Guide 21. Med Teach 2000;23:123-37.

13. Harden RM. The integration ladder: a tool for curriculum planning and evaluation. Med Educ 2000;34:551-7.

14. Kaliner MA, Del Giacco S, Crisci CD, et al. Requirements for physician training in allergy: key clinical competencies appropriate for the care of patients with allergic or immunologic diseases - a provisional position statement of the World Allergy Organisation. Allergy Clin Immunol Int - J World Allergy Org 2006;18:92-7.

15. Harden RM, Davis M. The core curriculum with options or special study modules. AMEE Education Guide 5. Med Teach 1995; 17:125-48.

16. Alahlafi A, Burge S. What should undergraduate medical students know about psoriasis? Involving patients in curriculum development: modified Delphi technique. BMJ 2005;330:633-6.

17. DuBois JM, Burkemper. Ethics education in US medical schools: a study of syllabi. Academ Med 2002;77:432-7.

18. Meekin SA, Klein JE, Fleishman AR, Fins JJ. Development of a palliative education assessment tool for medical student education. Academ Med 2000;75:986-92.

19. Weiss LB, Levison SP. Tools for integrating women's health into medical education: clinical cases and concept mapping. Academ Med 2000;75:1081-6.

20. Warner JO, Kaliner MA, Crisci CD, et al. Allergy practice worldwide: a report by the World Allergy Organisation Speciality and Training Council. Allergy Clin Immunol Int - J World Allergy Org 2006;18:4-10.

Available online at http://www.thepcrj.org 